\section{Relations amongst the populations}

\section{Eric Sunderland}

The Peoples of Southern Africa and Their Affinities. By G.T. Nurse, J.S. Weiner, and Trefor Jenkins. Clarendon:1985. Pp.409. £45, \$69.

THIs is the third volume in the Clarendon series Research Monographs on Human Population Biology. The earlier titles Aboriginal Man Adapting (by R.L. Kirk) and The Genetics of the Jews (by A.E. Mourant, Ada C. Kopeć and Kazimiera Dominiewska-Sobczak) were well received, and the present book merits a similarly enthusiastic reception.

In the preface, Nurse and his colleagues write:

Some previous work on the human biology of Southern Africa has tended towards the creation of false categories, by assuming sharp demarcations and convenient uniformities. We have preferred to consider the Khoisan, the Negroes and the Caucasoids, not only in their unity, but in their diversity, though the more bewildering diversity of the hybrid populations has come close to defeating us.

The authors have tried to find explanations of their own observations, as well as those of others, from their three individual perspectives - that of a physiologist/ palaeoanthropologist, a human geneticist well-grounded in clinical epidemiology, and a medically-qualified anthropologist with experience of the tropics and some knowledge of linguistics. This is a formidible array of expertise which has here been deployed to excellent effect.

The book opens with a chapter devoted to the environmental context within which man existed and exists in Africa, and this is followed by a succinct account of human origins (which are essentially African) and of human evolutionary development. Thus the scene is set, and it is established that in this development migration and thus genetic interchange is inextricably involved:

[from] perhaps as far back as $35000 \mathrm{BP}$... Khoisan or Khoisanoid populations were in evidence over the... area extending from Zambia and Zimbabwe southwards through the modern republic. ... The paucity during this long period and over this large territory of any groups diagnosed with certainty as Negroes, is phyletically highly significant.

It would thus seem that there was a Bushman/Hottentot basal population in southern Africa, upon which Negro, European and Asian groups were superimposed by migration at various later times, and to variable extents, and with which there was a measure of hybridization.

Logically, therefore, the book describes the biological attributes of the Khoi, the San and the Negroes (including a consideration of the incursions of the latter), and then proceeds to consider the seaborne immigrants from various parts of the world. Finally, the various hybrid communities are considered, including the Cape "coloureds", the Griqua and the Basters.

The nomenclature used in describing these many and diverse ethnic groups is complex, even bewildering unless one has some familiarity with the relevant literature. The tables (pp.299-346) are very helpful in identifying the various populations, though it is a pity there is no map to make things easier for the reader. However, the necessary facts about groups and their locations are painstakingly set out, and one can but be content with the detail and accuracy with which this information is presented.

In addition to description, modern biological anthropologists are very properly concerned with process - natural selection, the founder effect, random genetic drift, migration, demographic characteristics, health-status and much more besides. More generally they investigate the adaptive processes which have produced the biological constitution of the peoples concerned. Such processes - and all manner of related phenomena - are considered, explicitly or implicitly, throughout the book. There is discussion of morphology, anatomy, physiology, energy flow, pigmentation, monogenic factors, culture and technology, and ecology, to name but a few of the factors which, in toto, characterize, and indeed constitute, the distinctive adaptive complexes that are found among the populations of southern Africa.

The authors tell us that

There has been only negligible gene flow from Caucasoids into the Southern African Negroes in modern times, and most of the undoubtedly large genetic contribution made to them by the San and Khoi cannot be dated accurately. Much of it probably happened early.

Furthermore, while the affinities of the populations within southern Africa are considered in the book, it is conceded that "It is impossible to reconstruct the precise patterns of relationship among the African peoples". However, an attempt is made by looking at 23 sub-Saharan populations in terms of 32 alleles (five red cell antigen, two serum protein and four red cell enzyme systems), using a variant of principal components analysis known as correspondence analysis. The conclusion is that

The position in space of the various populations conforms very strikingly with the geographical distances between them, as well as with reconstructions of African pre-history which are becoming available from linguistic and archaeological data.

This is reassuring - such correspondence

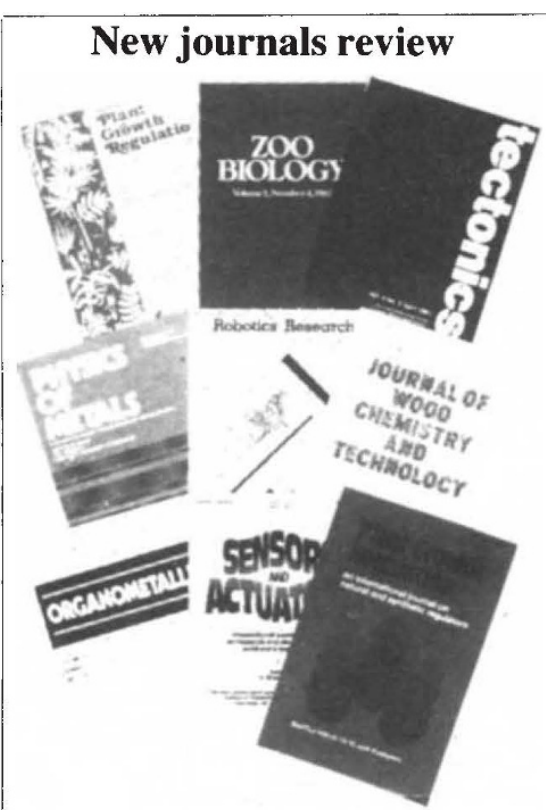

On 25 September Nature will publish the sixth annual review supplement devoted to science journals.

Criteria for inclusion of a journal in the 1986 issue are that:

(i) the first number appeared, or the journal was retitled, between June 1984 and May 1985 (the second cut-off date allows at least three issues of a journal to have been published. the minimum number on which a reasonable judgement can be based);

(ii) it is published at least three times a year;

(iii) the main language used is English.

Publishers and learned societies are invited to send four different issues of each suitable periodical, including the first and most recent numbers (if from outside the United Kingdom, by air mail) to: The Review Editor, Nature, 4 Little Essex Street, London WC2R 3LF. England. Subscription details for both 1986 and 1987 should be included.

is not always found - and suggests an overall coherence in the data of various kinds which have been examined. The same technique was used to consider the affinities of 42 southern African populations; here the authors say that "Perhaps the most interesting point is the extreme dissimilarity of the San populations to their Negro fellow-Africans".

The book concludes with tables of genetic polymorphisms, as well as a splendid bibliography, glossary, author index and subject index. Altogether, this is an outstanding book, scholarly yet written in lucid style. It should be read not only by those who have an interest in the peoples of southern Africa, but by anyone attempting to understand the nature and extent of population diversity in any part of the world.

Eric Sunderland, formerly Professor of Anthropology at the University of Durham, is Principal of the University College of North Wales, Bangor, Gwynedd LL57 2DG. UK. 